the difference is practically unimportant. As to what deaths registered as "continued fever" should be statistically considered as cases of "enteric fever" is a difficulty more easily stated than solved; but the important and essential point is that, where different localities are selected for comparison, the same classes of disease should be rigidly adhered to in the statistics of each, and this has been done in every case in the statistics given by me. With the above qualifications the figures were absolutely correct, and, under any circumstances, as correct as possible.

As regards the objection to the populations of the counties, I may say that, as the period of eight years to which the statistics refer consisted of parts of two decades, 1861-71 and 1871-81, and the annual variation of population in the counties is so small comparatively, the enumerated population of 1871 (one of the years included) is, under the circumstances, a sounder basis to go upon than any estimated population; in this I am following the practice of the Registrar-General in the case of the counties.

The conclusions at which I arrived were, "That diphtheria everywhere prevails more fatally in rural than in urban districts, and that the reverse holds good in the case of enteric fever." Some observations in Scotland have led Dr. Russell to the singular conclusion that in England "enteric fever is more fatal in rural districts than in towns." On this point I prefer statistics to analogy. Statistics, however, are one thing, and their interpretation is another; the latter I consider one of the most responsible duties of a medical officer of health. Assuming for the moment that the statistics of rural districts did give an equal degree of comparative mortality for diphtheria and enteric fever, it would by no means follow, as Dr. Russell infers, that the local causes of the two diseases existed in an equal degree; for whilst, owing to the usual age of the patients and the sudden onset of the disease, it is most exceptional to find a case of diphtheria imported into a rural district, cases of enteric fever are constantly so imported, and in many purely rural districts upwards of 50 per cent of the cases of enteric fever can be directly so traced. If correction for such cases were practicable, the inverse prevalence of diphtheria and enteric fever would be still more marked in statistics of mortality. I am, Sir, yours, \&c.,

Angust 26th, 1878 .

$$
\text { W. N. Thursfield, M.D., S.Sc.C. Camb. }
$$

\section{THE HEALTH OF TENBY.}

To the Editor of THE LANCET.

SIR,--In your article on the Health of English Wateringplaces in THE LANCET of the 17th inst., you call attention to the death-rate of various health-resorts, and say, truly enough, that "it has been complained that the RegistrarGeneral's areas are larger than those of the watering-places themselves." Tenby has just cause of complaint on this score, having attached to it not only thirteen rural parishes, but a very unhealthy parish in the borough of Pembroke, ten miles distant, where the zeal of the authorities in the cause of sanitation may be measured by the fact that the medical officer of health in that borough lately complained that his report had been several months on the table unread! and where the annual rate of mortality for the three months ending June 30 th last was 42 per 1000 ! With regard to the rural parishes immediately surrounding Tenby, they are remarkably free from disease, and a death in either of these is a novelty.

There is a manifest fallacy in estimating an annual deathrate from one quarterly return, as practised by the RegistrarGeneral. This is shown in comparing the average death-rate of Tenby and Herne Bay. For the quarter Tenby shows a mortality of 26.8 per 1000 , and Herne Bay 8.5 ; but for the preceding ten years the positions are reversed, the mortality of the former being $18 \cdot 2$, whilst that of the latter is 20.5 . Of course the quarterly deaths, from whatever cause, have to be multiplied by four to estimate the annual rate, and thus five deaths from zymotic diseases occurring in one quarter would be calculated as twenty per annum in the quarterly report, although no deaths from the same causes might take place in the other three quarters. In the same way, if a boat capsized in the bay, and five persons were unfortunately drowned, they would be quadrupled, as regards the annual rate, in the next quarterly report. It may be said that this calculation is as fair for one place as another, to which I reply, it is unfair to all.

Now I will come to facts. The actual number of deaths in the town of Tenby from July 1, 1877, to June 30, 1878, was 90. At a low estimate the population of Tenby (exclusive of visitors) was 5500 . This gives a death-rate of $16^{\circ} 4$, instead of $26 \cdot 8$ per thousand. Although we exclude visitors from the estimated population, we cannot exclude their deaths from our mortality lists; and we find that of the 90 who died 10 were visitors. This reduces the death-rate of residents to $14 \cdot 6$ per 1000 . Seven deaths occurred during the year from zymotic diseases (we are credited with 14)viz., 2 from convulsions during whooping cough ; 1 from pneumonia following measles; 2 from diphtheria (one brought from a distant town already ill with the disease, the other an isolated case) ; and 2 from "fever." This gives a death-rate of 1.3 per 1000 , instead of 3.59 , as it appears in the Registrar-General's return. Making a further analysis of our 90 deaths, we find that 19 were under one year, and 28 over 60 years of age, 8 being over 80 . Of the causes of death: 14 died of diseases of the brain ; 31 of affections of the heart and lungs ; 19 of kidney, bowel, and liver diseases; 3 of childbirth or maladies connected therewith; 2 from accident; and 7 from zymotic diseases, as before-mentioned. Climatic influences cannot be credited with the deaths of the ten visitors, for three died of apoplexy, two of intemperance, two of chronic cystitis, one of phthisis, one (an infant) of marasmus, and one child of diphtheria (the imported case already referred to). In the year 1873 there were seven deaths from zymotic diseases, in 1874 one, in 1875 eight, and in 1876 one. I observe that the Builder of the 24th inst. contains a letter from a Mr. Burns vehemently condemning the sanitary state of Tenby. To this letter a full and satisfactory answer will appear in due course.

Trusting you will insert this in your next issue, I am, Sir, your obedient servant, Douglas A. REID, M.D.

Church House, Tenby, August 27th, 1878.

\section{MUMPS; METASTASIS TO BRAIN. To the Editor of THE LANCET.}

SIR,-The following case is, I believe, as far as public record goes, unique in the sequence of its events. I have carefully examined the descriptions of munups by writers ordinarily accessible, and cannot find a parallel case. Medical friends, to whom I have referred, are equally unable to furnish any, either from their own experience or research. Watson's "Practice of Physic," vol. i., p. 297, third edition, after speaking of the transference of the disease from the parotid to the testicle, says :- "But sometimes a more serious transference takes place from the testicle to the brain. This I have never witnessed; but then, to say the truth, I have not often been called upon to treat the mumps, and my personal experience of it is limited. ..... Inflammation of the brain or its membranes has sometimes occurred on the disappearance of the parotid swelling, but it has much oftener supervened, I believe, upon the retrocession of the inflammation from the testicle or mamma."

Trousseau's ("Clin. Med.," vol. ii., Syd. ed.) description of mumps is most accurate and interesting. He records two cases of what he indicates as best designated by the term "febris testicularis"- a state of high fever, attended in one of the cases by delirium, a symptom not mentioned in the other. He does not seem to infer that there was in either case a retrocession of inflammation from the parotid to the brain or its membranes, but that there was general fever, attended with inflammation of the testicle. I would venture to sug. gest that, read by the light of the case which I am about to detail, there was in both cases "metastasis" to the brain first, and then from the brain to the testicle.

On April 16th a gentleman, aged twenty-six, called upon me to ask whether, having the mumps, he might go to the seaside. The left parotid was considerably enlarged, tense, and painful. I advised him to go home, keep warm, and take an aperient. As he left me, I said to him, jocularly, "Mind you don't take cold ; it may go either to your brain or your testicle." Four days later-i. e., April 20th-I was requested to see him at home. I found him feverish, rest- 